\title{
Morphine Patient Controlled Analgesia for Postoperative Analgesia in Patients Who Have Transplanted Cadaver Donor Kidneys
}

\author{
I. Madeira, R. Frada, J. Marvão, F. Cruz, M. Casal, and E. Costa
}

\begin{abstract}
Introduction. Patients who have chronic renal disease present challenges to anesthesiologists because of the sequelae of the underlying disease. Postoperative pain is usually mild to moderate after renal transplantation and is a concern because of underlying co-morbidities and variable responses of the graft. Effective postoperative pain management contributes to a a successful outcome after renal transplantation.
\end{abstract}

Methods. A retrospective study, based on the collected data from clinical process and registration of the acute pain unit.

Results. During 2007 and 2008, 124 patients were transplanted with cadaver donor kidneys. The final sample included 55 patients, namely $67 \%$ males and $33 \%$ females, whose ages range between 15 and 75 years (average, 47.23 years). Their American Society of Anesthesiologists physical status classification was 4 in $71 \%$ and 3 in $29 \%$.

Analgesia during surgery used a fentanyl, paracetamol and morphine protocol $(n=47)$ or fentanyl, paracetamol, morphine, and local anesthetic infiltration $(\mathrm{n}=8)$. The postoperative pain was quantified using a numerical rating scale $(0-4)$ with mean value of 1.07 on day 1 , a mean value of 1 on day 2 , and a mean value of 0.67 on day 3 . Postoperative analgesia with morphine patient-controlled analgesia was used for every patient, combined with paracetamol in $89 \%$ of cases. The average number of bolus demands was 60 with 26.4 effective boluses, the mean total administered dose was $26.6 \mathrm{mg}$. The major side effects were constipation (18\%), pruritus (14\%), nausea (13\%), and vomiting (1.8\%).

The following relations were significance: age and score of pain, pruritus and total dose of morphine, preoperative analgesia, and pain score on day 2.

Conclusions. Our results suggest that analgesia with morphine patient-controlled analgesia was an effective method to achieve control of postoperative pain in this population with few side effects.

\begin{abstract}
A FTER improvements in perioperative care and postoperative immunosuppression, renal transplantation has become the best therapeutic option for end-stage renal failure. It not only improves quality of life but also prolongs life. ${ }^{1}$ The 5 -year survival rate is approximately $70 \%$, whereas it is only $30 \%$ for a similar group of patients undergoing dialysis. ${ }^{2}$

Cases for patients who have end-stage renal failure are complex and present challenges to anesthesiologists because of the sequelae and co-morbidities. Because age is no longer a barrier for transplantation, one must consider associated morbidities. ${ }^{3}$ The perioperative care of these patients must be performed by multidisciplinary staff in an appropriate experienced ward. Failure to provide appropriate care for these patients has implications for graft survival and may increase morbidity. ${ }^{4}$
\end{abstract}

After renal transplantation postoperative pain is usually mild to moderate. Postoperative pain is a concern because of underlying co-morbidities and variable responses of the graft. Effective postoperative pain management contributes to successful outcomes. Improperly controlled pain may lead to agitation, tachycardia, hypertension, and an increased risk of respiratory complications. There are two options for analgesia: systemic or epidural. Systemic analgesia may cause concern

From the Oporto Hospital Center (I.M., R.F., J.M., F.C., M.C.), Hospital of Santo António, Anesthesiology Department; and the Instituto de Ciências da Saúde da Universidade Católica Portuguesa (E.C.).

Address reprint requests to Isabel Madeira, Largo Prof. Abel Salazar 4099-001 Porto, Portugal. E-mail: isabelnamadeira@ gmail.com 
Table 1. Sample's CRF Etiologies Distribution

\begin{tabular}{lc}
\hline \multicolumn{1}{c}{ Etiology } & Number of Patients \\
\hline Unknown & 20 \\
Segmental and local glomerulosclerosis & 7 \\
IgA nephropathy & 4 \\
Diabetic nephropathy & 4 \\
Chronic glomerulonephritis & 4 \\
Obstructive uropathy & 2 \\
Hypertension & 2 \\
LES & 1 \\
Genitourinary malformation & 1 \\
ADPRD & 1 \\
hereditary nephropathy & 1 \\
Mesangioproliferative glomerulonephritis & 1 \\
HSP & 1 \\
Acute pieelonephritis & 1 \\
Lithiasic chronic pielonephritis & 1 \\
Reflux & 1 \\
Nephrotic syndrome & 1 \\
Fibrillar glomerulonephritis & 1 \\
Glomerulosclerosis and tubulointersticial nephritis & 1 \\
\hline
\end{tabular}

LES, systemic eritematous lupus; ADPRD, autossomal dominant poliquistic renal disease; HSP, Henoch-Schonlein purpura.

with impaired graft function; whereas epidural analgesia is a risky technique in patients who were on dialysis previously, because of the platelet dysfunction and residual heparin associated with the dialysis itself. ${ }^{4-6}$

In our hospital, all patients undergo general anesthesia and systemic analgesia for postoperative pain control. They receive patient-controlled analgesia (PCA) with morphine and paracetamol ( $1 \mathrm{~g}$ three times daily). Intravenous opioids provide the mainstay of analgesia in Europe, with the majority of medical centers favoring the use of morphine by PCA. A minority of medical centers use fentanyl despite its preferable pharmacokinetic profile with fast onset and offset times. Fentanyl has a lesser tendency to cause accumulation of active metabolites that cause side effects. ${ }^{7}$ There is no strong evidence to support the use of one opioid over another in patients with renal impairment. In addition,

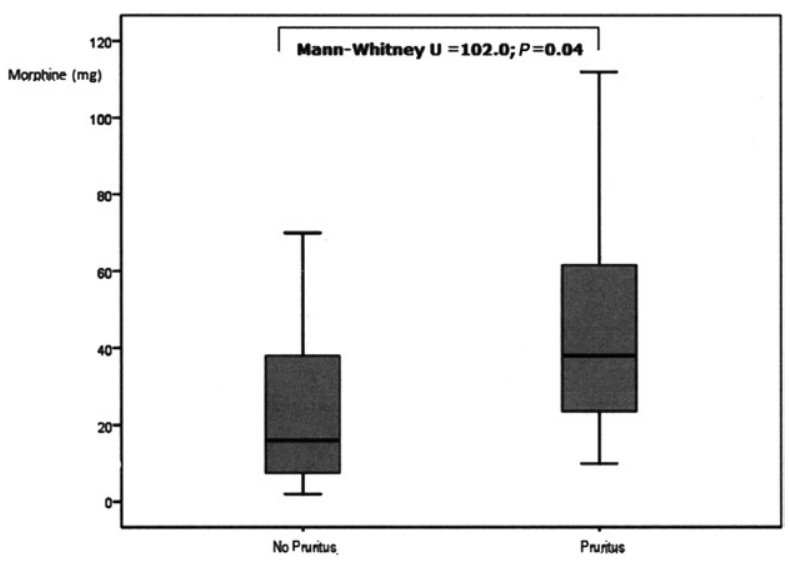

Fig 1. Pruritus and total dose of morphine (mg).

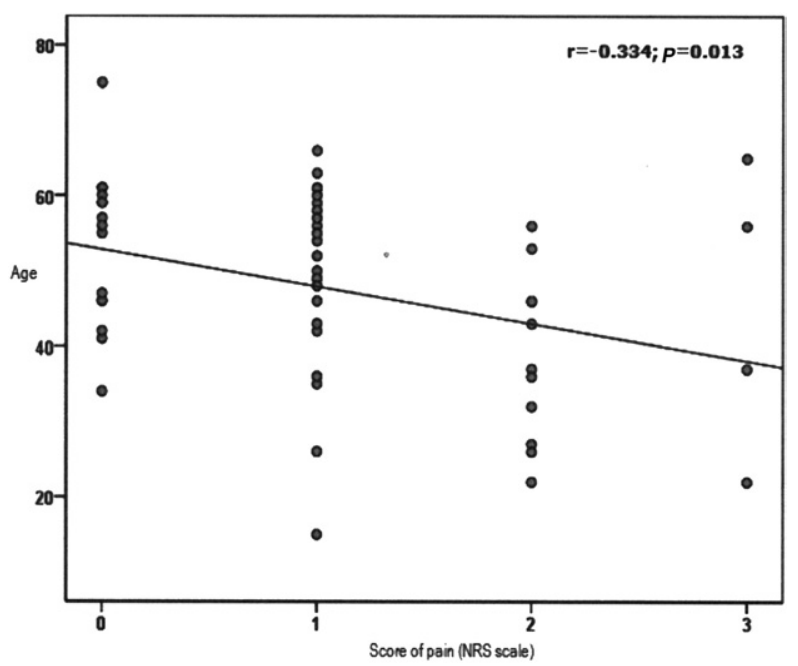

Fig 2. Age and outcome of pain.

despite the possibility of significant accumulation of potent metabolites, which may act in a negative-feedback loop to limit PCA, most medical centers use morphine with no apparent problems in this regard. A functioning graft contributes to effective analgesia. ${ }^{8}$

This study was to analyzes our analgesia protocol, reporting side effects and comparing them with the several patient characteristics.

\section{METHODS}

We performed a retrospective study, collecting data from clinical registers of the acute pain unit. We included data related to patient characteristics perioperatively and postoperatively after cadaver donor procedures in our hospital during 2007 and 2008. To characterize patients we used age, gender, American Society of Anesthesiologists physical status classification, co-morbidities, renal failure etiology, and previous renal transplantation. In the perioperative period we registered perioperatory analgesia. In the postoperative period we collected data on the level of pain, the use of PCA, the side effects, and graft function.

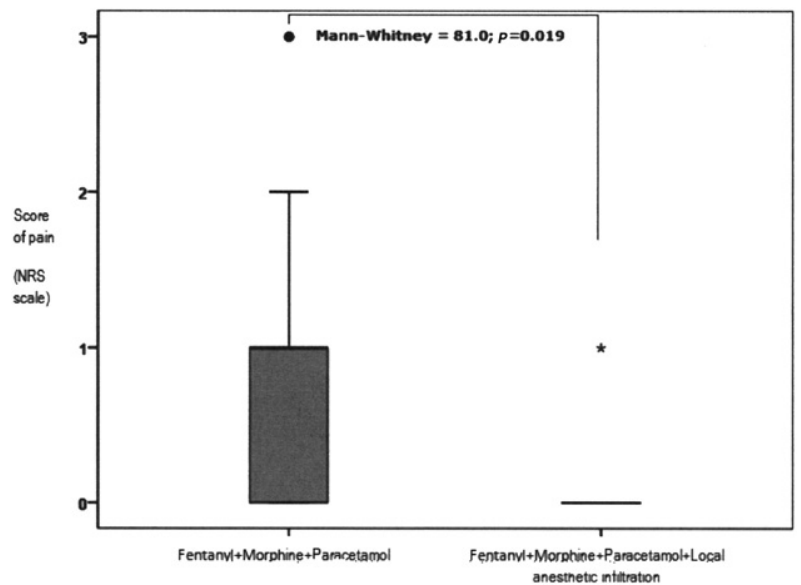

Fig 3. Perioperative analgesia and score of pain in day 2. 


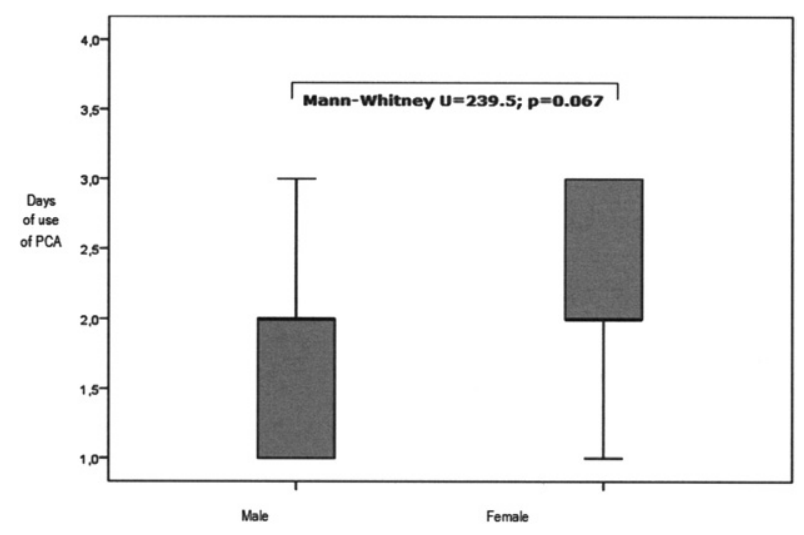

Fig 4. Gender and days of use of PCA.

The Statistical Package for Social Sciences (SPSS, version 15.0 for Windows, Inc. Chicago, IL, USA) was used to evaluate Kolmogorov-Smirnov test statistics for sample normality distribution. For comparisons between groups, we used the Student $t$-test whenever the parameters presented a gaussian distribution, and the Mann-Whitney test for a non-gaussian distribution. Spearman's rank correlation coefficient was used to evaluate relationships between data sets. Significance was accepted at $P<0.05$.

\section{RESULTS}

\section{Sample Data}

During 2007 and 2008, 124 patients were transplanted with cadaver kidneys in our hospital. Due to the lack of data our final sample included 55 patients including $67 \%$ males and $33 \%$ females with an age range of 15 to 75 years (average, 47.23). Their ASA physical status was 4 in $71 \%$ and 3 in $29 \%$.

Some patients did not initiate dialysis, therefore, the duration of dialysis varied between 0 and 384 months (average, 52.25). Six patients had undergone a previous renal transplantation; only 35 maintained a urinary output.

Co-morbidities in the sample were: hypertension $(\mathrm{n}=$ $35)$, cardiac dysfunction $(\mathrm{n}=11)$, metabolic disorders $(\mathrm{n}=$ $7)$, anemia $(n=4)$, respiratory pathology $(n=4)$, obesity $(\mathrm{n}=2)$, use of antiaggregants $(\mathrm{n}=7)$, and hypocoagulation $(\mathrm{n}=2)$. The etiology of renal failure was unspecified/ unknown in the majority of cases $(n=20)$. Segmental and focal glomerulosclerosis was the second most frequent cause. Table 1 shows the distribution of etiologies.

\section{Perioperative Period}

Perioperative analgesia was performed with a fentanyl + paracetamol + morphine protocol $(n=47)$ or a fentanyl +

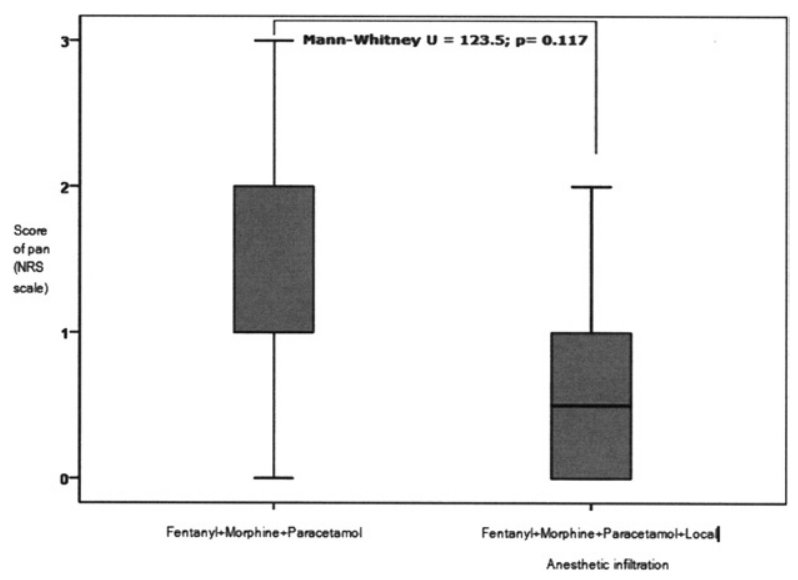

Fig 5. Perioperative analgesia and score of pain in day 1.

paracetamol + morphine + local anesthetic infiltration $(\mathrm{n}=8)$.

\section{Postoperative Period}

Postoperative pain was quantified using a numerical rating scale $(0-4)$; zero indicated a non-pain state and 4 indicated the worst imaginable pain: the mean pair rating was 1.07 on day $1,1.0$ on day 2 , and 0.67 on the day 3 .

Pain score evaluation was performed during the use of PCA with morphine a PCA with morphine was used for maximum of 3 days an (average, 1.91 days). Postoperative analgesia with morphine PCA was used on every patient and was associated with paracetamol in $89 \%$ of cases. The average number of demands was 60 with 26.4 effective boluses. The mean total dose administered was $26.6 \mathrm{mg}$. The major side effects reported were constipation (18\%), pruritus $(14 \%)$, nausea $(13 \%)$, and vomiting $(1.8 \%)$.

\section{Relationships Between Sets of Data}

Significance was observed for the following relations: pruritus and total dose of morphine, age and score of pain; perioperative analgesia, and score of pain on day 2 (Figs 1-3). A positive tendency was described for the following: gender and days of PCA use, and perioperative analgesia and pain score on day 1 (Figs 4 and 5). Evaluation of relationships between other sets of data (all the other patents characteristics and their relationship with use of PCA, score of pain, and side effects) showed no statistical significance.

Table 2 through 7 show the relationships between data sets.

Table 2. Test Statistics Comparison Based on Patient Gender

\begin{tabular}{|c|c|c|c|c|c|c|c|}
\hline Test & $\begin{array}{c}\text { Duration } \\
\text { of } \\
\text { Hemodialysis }\end{array}$ & $\begin{array}{c}\text { Duration of } \\
\text { Peritoneal } \\
\text { Dialysis }\end{array}$ & $\begin{array}{c}\text { Time Without } \\
\text { Urinary } \\
\text { Output }\end{array}$ & $\begin{array}{l}\text { Number of } \\
\text { Morphine } \\
\text { Demands }\end{array}$ & $\begin{array}{l}\text { Number of } \\
\text { Morphine } \\
\text { Boluses }\end{array}$ & $\begin{array}{c}\text { Total Dose of } \\
\text { Morphine }\end{array}$ & $\begin{array}{l}\text { Number of } \\
\text { Days of } \\
\text { PCA Use }\end{array}$ \\
\hline Mann-Whitney U & 324.500 & 270.000 & 270.000 & 331.000 & 329.500 & 311.000 & 239.500 \\
\hline Wilcoxon W & 495.500 & 973.000 & 441.000 & 502.000 & 1032.500 & 1014.000 & 942.500 \\
\hline Z & -.153 & -2.266 & -1.324 & -.036 & -.063 & -.395 & -1.835 \\
\hline Asymp sig. (2-tailed) & .879 & .023 & .186 & .971 & .950 & .693 & .067 \\
\hline
\end{tabular}




\section{DISCUSSION}

Our results suggested that analgesia using PCA with morphine was effective to control postoperative pain in this population with few side effects. Female patients used the PCA for longer periods than male patients. Higher pain scores were reported among younger patients. It is also clear that the infiltration of the incision site with local anesthetic provided lower pain scores.

\section{REFERENCES}

1. Zhang R, Kumar P, Ramcharan T, et al: Kidney transplantation: the evolving challenges. Am J Med Sci 328:156, 2004

2. UK Transplant website. Available at http://www.uktransplant. org.ukS. Accessed February 26, 2007
3. Rang ST, West NL, Howard J, et al: Anesthesia for chronic renal disease and renal transplantation. eau - ebu update series 4:246, 2006

4. Kehlet H, Holte K: Effect of postoperative analgesia on surgical outcome. Br J Anaesthesia 87:62, 2001

5. Modi MP, Shah VR: Epidural infusion of bupivacaine with morphine for pain relief after renal transplantation: a comparison with PCA intravenous morphine. J Anaesth Clin Pharmacol 25:277, 2009

6. Jankovic Z, Sri-Chandana C: Anaesthesia for renal transplant: recent developments and recommendations. Curr Anaesthesia Critical Care 19:247, 2008

7. Alpek AE, Kayhan Z: Patient-controlled epidural analgesia with morphine in renal transplant patients. Transplant Proc 32:613, 2000

8. Williams M, Milner QJ: Postoperative analgesia following renal transplantation-current practice in the UK. Anaesthesia $58: 712,2003$

Table 3. Test Statistics Comparison Based on Nausea

\begin{tabular}{|c|c|c|c|c|c|c|c|c|}
\hline Test & $\begin{array}{c}\text { Duration of } \\
\text { Hemodialysis }\end{array}$ & $\begin{array}{l}\text { Duration of } \\
\text { Peritoneal } \\
\text { Dialysis }\end{array}$ & $\begin{array}{c}\text { Time Without } \\
\text { Urinary } \\
\text { Output }\end{array}$ & $\begin{array}{l}\text { Number of } \\
\text { Morphine } \\
\text { Demands }\end{array}$ & $\begin{array}{l}\text { Number of } \\
\text { Morphine } \\
\text { Bolus }\end{array}$ & $\begin{array}{l}\text { Total Dose } \\
\text { of } \\
\text { Morphine }\end{array}$ & $\begin{array}{l}\text { Number of } \\
\text { Days of } \\
\text { PCA Use }\end{array}$ & Age \\
\hline Mann-Whitney U & 20.000 & 24.500 & 11.500 & 8.000 & 20.000 & 20.000 & 24.500 & 17.500 \\
\hline Wilcoxon W & 21.000 & 25.500 & 1496.500 & 1493.000 & 1505.000 & 1505.000 & 1509.500 & 1502.500 \\
\hline Z & -.441 & -.316 & -1.144 & -1.197 & -.441 & -.441 & -.172 & -.599 \\
\hline Asymp. sig. (2-tailed) & .659 & .752 & .253 & .231 & 659 & .659 & .863 & .549 \\
\hline Exact sig. [2×(1-tailed Sig.) $]^{\star}$ & .764 & .909 & .436 & .327 & .764 & .764 & .909 & .655 \\
\hline
\end{tabular}

*Not corrected for ties.

Table 4. Test Statistics Comparison Based on Constipation

\begin{tabular}{|c|c|c|c|c|c|c|c|c|}
\hline Test & $\begin{array}{c}\begin{array}{c}\text { Duration } \\
\text { of }\end{array} \\
\text { Hemodialysis }\end{array}$ & $\begin{array}{l}\text { Duration of } \\
\text { Peritoneal } \\
\text { Dialysis }\end{array}$ & $\begin{array}{c}\text { Time Without } \\
\text { Urinary } \\
\text { Output }\end{array}$ & $\begin{array}{l}\text { Number of } \\
\text { Morphine } \\
\text { Demands }\end{array}$ & $\begin{array}{c}\text { Number of } \\
\text { Morphine } \\
\text { Bolus }\end{array}$ & $\begin{array}{c}\text { Total Dose } \\
\text { of } \\
\text { Morphine }\end{array}$ & $\begin{array}{l}\text { Number of } \\
\text { Days of } \\
\text { PCA Use }\end{array}$ & Age \\
\hline Mann-Whitney U & 98.000 & 200.000 & 200.000 & 178.500 & 195.500 & 199.500 & 203.500 & 111.000 \\
\hline Wilcoxon W & 1133.000 & 255.000 & 1235.000 & 1213.500 & 1230.500 & 1234.500 & 258.500 & 1146.000 \\
\hline Z & -2.774 & -1.094 & -.639 & -1.015 & -.644 & -.557 & -.513 & -2.491 \\
\hline Asymp. sig. (2-tailed) & .006 & .274 & .523 & .310 & .520 & .578 & .608 & .013 \\
\hline
\end{tabular}

Table 5. Test Statistic Comparison Based on Pruritis

\begin{tabular}{|c|c|c|c|c|c|c|c|c|}
\hline Test & $\begin{array}{c}\text { Duration } \\
\text { of } \\
\text { Hemodialysis }\end{array}$ & $\begin{array}{c}\text { Duration of } \\
\text { Peritoneal } \\
\text { Dialysis }\end{array}$ & $\begin{array}{c}\text { Time Without } \\
\text { Urinary } \\
\text { Output }\end{array}$ & $\begin{array}{l}\text { Number of } \\
\text { Morphine } \\
\text { Demands }\end{array}$ & $\begin{array}{l}\text { Number of } \\
\text { Morphine } \\
\text { Bolus }\end{array}$ & $\begin{array}{c}\text { Total } \\
\text { Dose of } \\
\text { Morphine }\end{array}$ & $\begin{array}{l}\text { Number of } \\
\text { Days of } \\
\text { PCA Use }\end{array}$ & Age \\
\hline Mann-Whitney U & 143.000 & 182.000 & 183.000 & 100.500 & 100.000 & 102.000 & 92.500 & 139.000 \\
\hline Wilcoxon W & 179.000 & 1310.000 & 1311.000 & 1228.500 & 1228.000 & 1230.000 & 1220.500 & 175.000 \\
\hline Z & -1.075 & -.287 & -.140 & -2.089 & -2.102 & -2.054 & -2.494 & -1.171 \\
\hline Asymp. sig. (2-tailed) & .282 & .774 & .889 & .037 & .036 & .040 & .013 & .242 \\
\hline Exact sig. [2×(1-tailed Sig. $)]^{\star}$ & .294 & .898 & .916 & .035 & .035 & .040 & .021 & .252 \\
\hline
\end{tabular}

${ }^{\star}$ Not corrected for ties. 
Table 6. Correlations for All Data

\begin{tabular}{|c|c|c|c|c|c|c|c|c|}
\hline & Age & $\begin{array}{l}\text { Duration of } \\
\text { Hemodialysis }\end{array}$ & $\begin{array}{l}\text { Time Without } \\
\text { Urinary } \\
\text { Output }\end{array}$ & $\begin{array}{c}\text { Duration of } \\
\text { Peritoneal } \\
\text { Dialysis }\end{array}$ & $\begin{array}{c}\text { Total } \\
\text { Dose of } \\
\text { Morphine }\end{array}$ & $\begin{array}{l}\text { Number of } \\
\text { Days of } \\
\text { PCA Use }\end{array}$ & $\begin{array}{l}\text { Number of } \\
\text { Morphine } \\
\text { Bolus }\end{array}$ & $\begin{array}{l}\text { Number of } \\
\text { Morphine } \\
\text { Demands }\end{array}$ \\
\hline \multicolumn{9}{|l|}{ Age } \\
\hline Pearson Correlation & 1 & .112 & -.019 & -.435 & -.154 & -.200 & -.170 & .084 \\
\hline Sig. (2-tailed) & & .417 & .889 & .001 & .263 & .143 & .214 & .541 \\
\hline $\mathrm{N}$ & 55 & 55 & 55 & 55 & 55 & 55 & 55 & 55 \\
\hline \multicolumn{9}{|l|}{ Duration of hemodialysis } \\
\hline Pearson Correlation & -.112 & 1 & .134 & -.147 & .077 & .055 & .064 & -.012 \\
\hline Sig. (2-tailed) & .417 & & .329 & .285 & .578 & .691 & .640 & .929 \\
\hline $\mathrm{N}$ & 55 & 55 & 55 & 55 & 55 & 55 & 55 & 55 \\
\hline \multicolumn{9}{|c|}{ Time Without Urinary Output } \\
\hline Pearson Correlation & -.019 & .134 & 1 & -.149 & -.082 & -.134 & -.074 & -.046 \\
\hline Sig. (2-tailed) & .889 & .329 & & .278 & .550 & .329 & .594 & .739 \\
\hline $\mathrm{N}$ & 55 & 55 & 55 & 55 & 55 & 55 & 55 & 55 \\
\hline \multicolumn{9}{|l|}{$\begin{array}{l}\text { Duration of peritoneal } \\
\text { dialysis }\end{array}$} \\
\hline Pearson Correlation & -.435 & -.147 & -.149 & 1 & -.102 & .067 & -.098 & -.104 \\
\hline Sig. (2-tailed) & .001 & .285 & .278 & & .461 & .629 & .477 & .448 \\
\hline $\mathrm{N}$ & 55 & 55 & 55 & 55 & 55 & 55 & 55 & 55 \\
\hline \multicolumn{9}{|l|}{ Total dose of morphine } \\
\hline Pearson Correlation & -.154 & .077 & -.082 & -.102 & 1 & .545 & .99 & .727 \\
\hline Sig (2-tailed) & .263 & .578 & .550 & .461 & & .000 & .000 & .000 \\
\hline $\mathrm{N}$ & 55 & 55 & 55 & 55 & 55 & 55 & 55 & 55 \\
\hline \multicolumn{9}{|c|}{ Number of days of PCA use } \\
\hline Pearson Correlation & -.200 & .055 & -.134 & .067 & .545 & 1 & .538 & .431 \\
\hline Sig. (2-tailed) & .143 & .691 & .329 & .629 & .000 & & .000 & .001 \\
\hline $\mathrm{N}$ & 55 & 55 & 55 & 55 & 55 & 55 & 55 & 55 \\
\hline \multicolumn{9}{|c|}{ Number of morphine bolus } \\
\hline Pearson Correlation & -.170 & .064 & -.074 & -.098 & .996 & .538 & 1 & .727 \\
\hline Sig. (2-tailed) & .214 & .640 & .594 & .477 & .000 & .000 & & .000 \\
\hline $\mathrm{N}$ & 55 & 55 & 55 & 55 & 55 & 55 & 55 & 55 \\
\hline \multicolumn{9}{|l|}{$\begin{array}{l}\text { Number of morphine } \\
\text { demands }\end{array}$} \\
\hline Pearson Correlation & .084 & -.012 & -046 & -.104 & .727 & .431 & .727 & 1 \\
\hline Sig. (2-tailed) & .541 & .929 & .739 & .448 & .000 & .001 & .000 & \\
\hline$N$ & 55 & 55 & 55 & 55 & 55 & 55 & 55 & 55 \\
\hline
\end{tabular}


Table 7. Score of Pain in Day 1 Using Analysis of Variance

\begin{tabular}{|c|c|c|c|c|c|}
\hline & Sum of Squares & df & Mean Square & $\mathrm{F}$ & Sig. \\
\hline \multicolumn{6}{|l|}{ Age } \\
\hline Between groups & 1431.627 & 3 & 477.209 & \multirow[t]{3}{*}{3.189} & \multirow[t]{3}{*}{.031} \\
\hline Within groups & 7631.901 & 51 & 149.645 & & \\
\hline Total & 9063.527 & 54 & & & \\
\hline \multicolumn{6}{|l|}{ Sex } \\
\hline Between groups & 1.208 & 3 & .403 & \multirow[t]{3}{*}{1.885} & \multirow[t]{3}{*}{.144} \\
\hline Within groups & 10.901 & 51 & .214 & & \\
\hline Total & 12.109 & 54 & & & \\
\hline \multicolumn{6}{|c|}{ Duration of hemodialysis } \\
\hline Between groups & 58370.208 & 3 & 19456.736 & \multirow[t]{3}{*}{3.763} & \multirow[t]{3}{*}{.016} \\
\hline Within groups & 263694.229 & 51 & 5170.475 & & \\
\hline Total & 322064.436 & 54 & & & \\
\hline \multicolumn{6}{|c|}{$\begin{array}{l}\text { Duration of peritoneal } \\
\text { dialysis }\end{array}$} \\
\hline Between groups & 5.539 & 3 & 1.846 & \multirow[t]{3}{*}{.141} & \multirow[t]{3}{*}{.935} \\
\hline Within groups & 667.842 & 51 & 13.095 & & \\
\hline Total & 673.382 & 54 & & & \\
\hline \multicolumn{6}{|c|}{ Time without urinary output } \\
\hline Between groups & 1.298 & 3 & .433 & \multirow[t]{3}{*}{.836} & \multirow[t]{3}{*}{.480} \\
\hline Within groups & 26.411 & 51 & .518 & & \\
\hline Total & 27.709 & 54 & & & \\
\hline \multicolumn{6}{|l|}{$\begin{array}{l}\text { Number of morphine } \\
\text { demands }\end{array}$} \\
\hline Between groups & 18233.968 & 3 & 6077.989 & \multirow[t]{3}{*}{.958} & \multirow[t]{3}{*}{.420} \\
\hline Within groups & 323576.760 & 51 & 6344.642 & & \\
\hline Total & 341810.727 & 54 & & & \\
\hline \multicolumn{6}{|c|}{ Number of morphine bolus } \\
\hline Between groups & 3024.827 & 3 & 1008.276 & \multirow[t]{3}{*}{1.946} & \multirow[t]{3}{*}{.134} \\
\hline Within groups & 26427.901 & 51 & 518.194 & & \\
\hline Total & 29452.727 & 54 & & & \\
\hline \multicolumn{6}{|c|}{ Total dose of morphine } \\
\hline Between groups & 3024.757 & 3 & 1008.252 & \multirow[t]{3}{*}{1.993} & \multirow[t]{3}{*}{.127} \\
\hline Within groups & 25803.502 & 51 & 505.951 & & \\
\hline Total & 28828.258 & 54 & & & \\
\hline \multicolumn{6}{|c|}{ Number of days of PCA use } \\
\hline Between groups & 8.157 & 3 & 2.719 & \multirow[t]{3}{*}{7.541} & \multirow[t]{3}{*}{.000} \\
\hline Within groups & 18.389 & 51 & .361 & & \\
\hline Total & 26.545 & 54 & & & \\
\hline
\end{tabular}

